\title{
Smart grids investigation and analysis in terms of cost benefits
}

\author{
B. Rubini ${ }^{1 *}$, N. Shanmugasundaram ${ }^{2}$, S. Pradeepkumar ${ }^{3}$ \\ ${ }^{1}$ Department of EEE, Vels Institute of Science, Technology and Advanced Studies (VISTAS), Chennai, India. \\ ${ }^{2}$ Department of EEE, Vels Institute of Science, Technology and Advanced Studies (VISTAS), Chennai, India. \\ ${ }^{3}$ Department of EEE, Vels Institute of Science, Technology and Advanced Studies (VISTAS), Chennai, India. \\ *Corresponding author E-mail: rubini.se@velsuniv.ac.in
}

\begin{abstract}
Currently, different advanced technologies are implemented in power networks, with aim to improve power quality and reliability of grid operation. Naturally, Distribution Automation and Management Systems (DAMS), Smart power equipment, Advanced Metering Structure, Distributed Energy Resources and/or systems Demand Response are implemented in electricity distribution networks. Smart Grid Solutions coordinate different advanced technologies in an efficient energy management system. Outline Smart Grid Solutions, with investments of estimation, possible benefits and operation costs, is presented in this article, with estimation of cost-effectiveness in a lifetime of particular systems.
\end{abstract}

Keywords: Distribution of electricity, automation management systems, distribution automation systems, smart grid.

\section{Introduction}

Smart Grid Solutions (SGS) should meaningfully improve quality, reliability and efficiency of power distribution, as well as minimize costs of power in network operation. The task is comparison with related costs, quantification of benefits delivered by SGS and to estimate the real cost-effectiveness of such investments. In electricity distribution network (EDN-Provides with the two way communication model that will provide secure and adequate power provided users and utilities level energy consumption data directly to the user for up-to-date will allow smart meters to provide real-time) are analyzed Benefits and costs of SGS applied in this article.

Aimed to improve efficiency of EDN operation, SGS involve different technologies as showed in Fig. 1.In the specific areas they can be gathered:

1. Smart network operation shows the implementation of smart power equipment with Distribution Automation Systems (DAS).

2. Smart metering: Meter Reading (AMR-for electric current measuring(by measuring the magnetic field created around the conductor) and Meter Data Management(MDM-utilities to support the loading, validation, editing and estimation of meter data performs long-term data storage and management for the enormous quantities of data delivered by smart metering systems), implementation of Advanced Metering Infrastructure (AMI-refers to systems that measure, collect, and analyze energy usage, and communicate with metering devices) with Automated (remote section).

3. Smart consumption: A Platform for Power Grid Convergence Control Strategies- Demand Response systems (DRS) and monitoring, modeling and optimal management control.

4. Smart generation: control of Distributed Energy Resources (DER-aggregated to provide power necessary to meet regular demand) and monitoring, modeling and optimal management control.

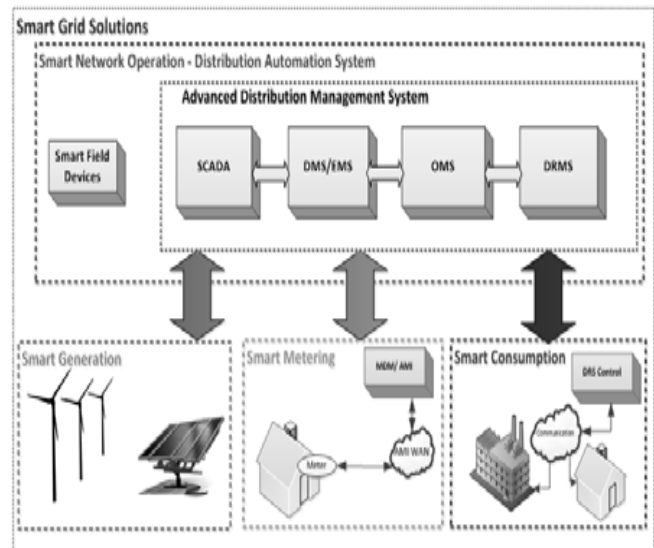

Fig. 1: Main technologies of SGS

Smart operation of EDN implies two-way communication model \& implementation of Distribution Automation Systems (DAS) with the subsequent modules:

- Convergence Control System Software, including basically four systems: DMS/EMS (Distribution/Energy Management System), (Outage Management System) OMS, SCADA, DRMS (Demand Response Management Systems) incorporated in one solution - Advanced DMS it is called (ADMS).

- Data's are transferred for high speed over wide areas to support Communication system.

- Hardware Centralized Control System, typically involved User workstations, Data Center servers are Primary and Disaster Recovery Data Center servers.

- Remotely controlled equipment in power grid like Field power equipment (fault indicators, load breaking switches and regulators voltage/capacitors including Motor drives) with communication subsystem (line communication modems or remote terminal units with radio).

Providing the full network control of ADMS is the central intelligence of DAS, mathematical modeling and single user 
interface. Network supports ADMS visualization (geographical and schematic), access to comprehensive technical database, network monitoring and control, simulation studies and surrounding for real-time control and historical data access-HAD (Exchanged Archived Process Data to Deal with Real-Time Data). Web technologies, energy Storages, as well as wide power functions are set of real numbers:

- To support switching execution, switching scheduling, fault management and emergency situations are Network operation functions in real-time network operation, typically used by Operators.

- Calculation of network operation state of Fundamental power functions (Power Flow and State Estimation), "inhabitant" typically functions are automatically triggered by system.

- To optimize operation of voltages and power flows from Network optimization functions, typically used by Control Center support engineers for short-term operation planning.

- To analyze short-circuits by Network analysis and Reporting functions, typically used by engineers in simulation mode with contingency problems, equipment rating, relay protection setting, location of harmonic pollution-can cause pollution within distribution power systems, and provide about power outages reports, losses, etc.,.

- Investment and planning departments engineers used (medium-term) Network long-term Process for development investigated by functions and network design of maintenance planning analysis, Network development and construction part.

- Smart meter son customer side to imply AMI implementation smart metering, to communicate with meters using Communication system and secure meter analysis and reporting tool to upload data from meters, data processing survey is taken by MDM.

Usually AMI consists of the following modules:

- Two-way communication Auxiliary part to provide commanding signals, accept data requests ,(upload) data input and Smart meters - which are used automatic meter reading for the measuring of utilization on customer side, in meter reading of storage of data.

- Meters and two way communication nodes between data and signals communication which is used for Communication network. Different communication technologies can be used (wireless Power Line Carrier or private radio, fiber optic/private wire IP networks or public mobile networks source, IP networks).

- Pre-processing and analysis for Network Management System (NMS), data storage and analysis to provide the information in useful from the utility by the AMI host system and Meter Data Management system that manages (Billing system, ADMS, web services, etc.).

DRS technologies implies delivers electricity from suppliers to consumers using two way communications to control appliances at consumers home (indirectly or directly)to Smart consumption, with agreement of the customer and with his participation in a assured "demand response program". Power system peak load aimed on reducing in DRS, quality is without substantial contravention of supply. Methodology based structure of the new private model is considered "peak-load" of generators could be ducked and overall system operation costs reduced as well as $\mathrm{CO} 2$ pollution also reduced.

Consist of the following modules based on DRS:

Analysis of operation network and execution of schedule created by DRS programs which implemented by based on (DRMS) Demand Response Management System is software applications. Modules are:

Should be part of ADMS, but is recognized as independent system in some applications.

- DRS of web portals, which accomplishes of customers participation, with their applications, signing contracts, tracking of DRS event results, compensations, etc.
- Master control system DRS, which transform programs DRMS to carrying signals out (e.g.in Direct control systems to local devices control signals or to customers statements in subsidiary control systems).

- Communication system DRS (e.g. private IP network or public mobile provider, AMI, radio system, power network, etc.).

- Local devices control DRS (e.g. control home systems, local PLC, Electrical (Smart meters), Control load switches, programmable communicating thermostats, etc.).

- Smart technologies Generation involves for DER, Design, monitoring and (optimal) control. Currently, (wind-farms and solar systems specifically), DER are connecting to power network in a large scale. Meaningfully changing old-style in distribution networks for "one-way" power flow, thus risking traditional design and protection system. The new Analysis and their impact on operation network of DER connections is compulsory and probably mathematical ADMS and control engines.

- Smart generation includes:

Local control devices DER with the transfer of data between two or more devices not located at the same site is called remote communication,

Master system ADMS for remote monitoring and control optimal dispatch and setting of protection considering Applications for DER analysis of ADMS.

\section{Benefits of smart grid}

Forecast Smart Grid solutions complete digital automation networks of distribution power, from the production to the customer side, to improve reduce costs of operation, reliability and efficiency of supply and SGS benefits are inclusive and higher relisted below:

- Network reliability Improved and minimization of outage time. Classy technologies of Self-healing reduce outage values and improves meaningfully reliability of power supply time to minimal.

- With higher utilization of existing/expensive power equipment implies to reduce operational cost and network construction costs.

- Innovation of new technologies are response to natural disasters and human interruptions and efficient identification for secure networks to implies optimal management of distributed generation production.

- Active customers - in Changes in electric usage by end-use customers from their normal consumption patterns in response to changes in the price of electricity over time programs are participating and having possibility to retail control of their consumption.

Benefits, from SGS implementation in distribution networks resulting, are scrutinized in comparison with the rate of (EEIA) "throughout the year in distribution network electric energy injected". Worldwide Commercial models functional in electrical sectors are changed, from structured to open economy and fully deregulated. For generating revenue Utilities have different commercial models, will be compared with EEIA benefits and costs, as common dimension in each economy [1 - 2].

A consistent and accurate data from state estimation is required for smart grid operations in real time. However, state estimation is exposed to data documentation process parameters maintenance, activities and security attacks, in which introduce errors and meter measurements can avoid the conventional bad data detection. The performance of attacking strategies proposed and countermeasure through numerical simulations in IEEE test systems with both synthetic and real data were evaluated from Independent System Operator [15].

\subsection{Benefits of DAS}


Central intelligence-service to both external and internal threats DAS is Advanced DMS (ADMS), which contains (mathematical) modeling of power network and set of calculation engines and algorithms to provide incident management, analysis, network operation, optimization, reporting and long-term planning. ADMS are applied calculation results in field with OMS modules and SCADA, to impart information and execution field part is important targets, to achieve Power Distribution Company (PDC) or a Utility. Benefits DAS [1-2] can be separated as:

- Minimization of power losses: DMS network operation implemented in the Optimal Network Reconfiguration may provide minimization of power losses [3-5]. Besides, improve voltage quality DMS Volt/Var and reduce losses as well [6-8], as well as Energy Audit implies tracing and reducing non-technical losses. The breakdown of electrical energy losses in networks distribution is presented in Fig.2. Coordinated application of results of DMS functions in network operation may bring $10-15 \%$ minimization of power losses, or of approximately $1 \%$ EEIA benefit [2].

- Minimization of operation costs: meaningfully DAS outage time will decrease, switching operation terminated and maintenance costs, and also energy not delivered by the suppliers penalties finally paid by PDC to customers. Direct costs of PDC to manage incidents in power network will reduce $0.4 \%$ procurement value of EEIA [2], while benefit of reduced penalties, if paid to customers, can reach the value of $4 \%$ EEIA[2].

- Minimization of network construction costs:for DMS optimal power restoration functions, network strengthening and longterm scheduling will improve utilization of facilities and rescheduling of investments, providing benefits $0.5-1 \%$ EEIA[2].

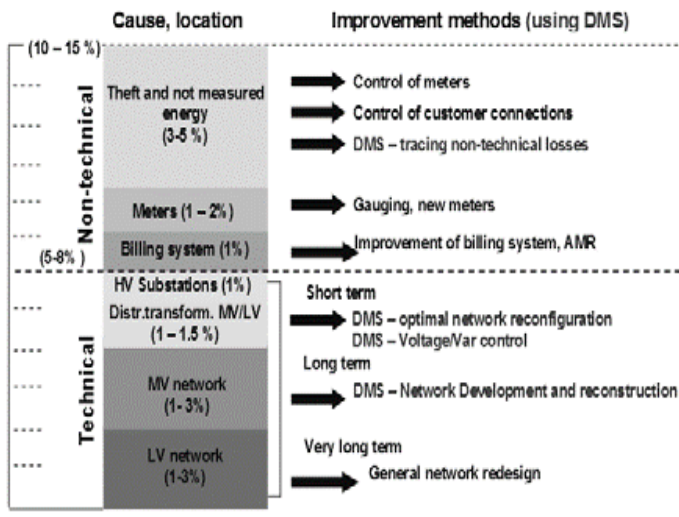

Fig. 2: Breakdown of power losses

The total DAS benefits possibly will reach annually:

1. $2 \%$ EEIA procurement value, if PDC doesn't pay penalties for outages to customers, or upto.

2. $6 \%$ EEIA procurement value, if PDC pays penalties for outages.

Benefits of AMI:

Benefits in several areas will bring AMI system of Application:

- Automated meter reading will improve Data processing and billing of customers, will reduce meters, reading costs, improve accuracy of consumption data, as well as improve payment of electricity bills. Old-style meter readings were operated manual, with cost wise labor and field cost are high. Procurement side not coordinated with low accuracy. Meter reading manually is changed into Automated will avoid labor and field costs (approx. 1 Eur/meter reading costs in 4 times per year is $2 \%$ EEIA), will recover financial income with benefits in range $1-2 \%$ EEIAwhereas greater accuracy and billing of customers.

- Data consumption and power measurements of AMI are very accurate synchronized with power flow calculations, DMS with integrated Energy Audit, will accelerate theft detection, providing benefits in range $1-2 \%$ EEIA[2].

- On customer side in real-time to get status and measurements, or to receive "trouble calls" in case of incidents will be used by Infrastructure AMI by Outage Management System. Administration process it is meaningfully improving outage in Low Voltage networks and reducing outage time. Similarly to DAS, benefits will be in range from $0,5 \%$ PDC costs for EEIA, up to $4 \%$ if penalties EEIA are paid by PDC to customers.

- Control system and controlled devices Communication between Demand Response will support Infrastructure AMI efficiently, reducing investments in DRS communication system.

\subsection{May reach annually the total AMI benefits}

- $6 \%$ EEIA procurement value, if PDC doesn't pay penalties for outages to customers, or upto

- $10 \%$ EEIA procurement value, if PDC pays penalties for outages.

\subsection{DRS benefits}

Primarily to reduce peak load on the system or local level Demand Response is used to avoid emergency situation for the reason that of non-adequate in the production or network side power capacity. However, currently in deregulated electricity environment, DRS is used as well as "virtual generators" and play active role on electricity market. In this investigation, "Utility tool" as for peak load management DRS will be considered, bringing the following benefits:

- The network level Peak load minimization of power and energy costs in peak hours leading directly to minimization.Thepriceofare2-5timespower/energy in peak hours higher than the price in off-peak times. Reduce DRS peak power in range $2-10 \%$, technology will be implemented and the number of participants, advantage will be in range 10 - 12\%EEIA.Network reliability Increased available capacity of operational network margin without exceeding is not loaded up to maximum. In large misbalances of energy, DRS finally to reduce black-outs.

- Facilities, rearranging investments costly in network construction, providing benefits in range of 1\%EEIA.

The total DRS benefits possibly will reach $12 \%$ EEIA procurement value annually.

\subsection{Management DER benefits}

Management of DER Smart capacities in distribution network may bring minimization of power losses, as well as minimization of peak-loads or overloads on the network and local level. Since DER management is still in development phase and first implementations have just started, there is no yet real experience in field, therefore it will not be considered in this analysis.

\section{Investment in smart grid system}

Investments of SGS concept in all groups are analyzed in this chapter:

SGS reserves comprise equipment in field, computer hardware, systems communications, reliable software, provided services, trainings and support. Smart Grid Systems integrates and coordinates advanced technologies in an efficient energy management system, to provide highest benefits out of huge investments.

DAS investments comprise the following sectors:

- Hardware and Software ADMS, installed in Data Server (main and back-up) Centers and (user's workstations) Control Centers, including data engineering, customization, delivery, training and testing of the system. 
- Substation Automation System sor (RTU) Remote Terminal Units,(MV/LV substations or pole mounted switches) implemented in HV Substations and many locations in MV network, (transducers, relays)including equipment for signal conversion,(power supply, assembling), testing and commissioning of the system ancillary equipment and services.

- $\quad$ Communication system (fiber-optic, radio, mobile providers), including system design. Licenses, deliver, training, testing and commissioning of the system.

- Remote control actions capable for Power equipment (motorized power switches on poles, Ring Main Units in MV/LV substations, voltage boosters, etc.)

Assurance level of the Distribution network has to be automated and using optimization steps to be capable for efficient remote control and execution of ADMS, which implies automation of all HV Substations and critical MV network points (3 - 4 automated points per feeder). Using several examples and real cases [2], considering all essential investments, $12 \%$ EEIA procurement value estimated level of DAS investment costs.

AMI investments include:

- Communication modules witch measurements Meters, installation and testing on-site including delivery. Data Server Centers are implemented, Network Management Software, including Software and Hardware, and testing.

Usual investments are in $40 \%$ EEIA procurement value AMI range 120 - 140 Eur/meter or approximately.

\section{Investments DRS include}

- Management Software DRS, Centers are implemented Data Server, including Software and Hardware, delivery and testing.

- Communication system DRS, system design including, licenses, delivery and communication equipment of installation, testing and implementation of the system. Currently, AMI is regularly used as communication system between DRS center and in case of "direct load control "of end consumer's infrastructure. Recently, for exchange of information, web-portal and internet is used.

- Local Devices on DRS consumer side, liable on technology applied, different kind of meters and signal receivers, home automation technology, control switches, AMI meters, etc. Investments of DRS with direct load control practical of 20 $\%$ EEIA in wide areas are in range of procurement value.

\section{Cost benefit analysis}

In the life time Benefits of SGS systems the cost/benefit analysis will include with all costs. Practical Analysis is example of a highest PDC with 1000 MW peak load and estimated EEIA of $4000 \mathrm{GWh} /$ year.

The procurement value of EEIA is using average procurement price of $30 \mathrm{Eur} / \mathrm{MWh}$, approximately 120 Million Euro (MEur).

SGS total initial investment costs, as analyzed in chapter 3, would be $72 \%$ EEIA or 86,4 MEur.

Beside initial investment cost, SGS system in operation would require assured "operation" and "maintenance" costs (O\&M), which are annually $2-3 \%$ of investment cost, as well as annual depreciation has to be accounted with additional 5\% for this kind of equipment.

Therefore, annual O\&M and depreciation $8 \%$ of initial outlay costs, or around 6,9 MEur/year.

A system hired the base stations as relays and formulated the electricity costs-based upon the regulation errors and the packets loss model.

Specifically, the utility company selects the relaying bandwidth to reduce its electricity costs, and the relay picks the base price to increase its profits [16].
For power outages to customers PDC is paying a assured compensation, as discussed in chapter 2 of this paper on the AMI which has impact and level of DAS benefits. SGS Annual benefits are in the range between $20 \%$ of EEIA is not paid if such compensation, up to $28 \%$ is paid to customers (between 24 and 33,6 MEur/year).

Sensitivity on the glassy of compensation paid to Customers will be considered SGS benefits.

The system operation is considered period of 10 years, which is close to the overall time of SGS equipment. SGS in the initial year of operation will start providing savings (only half benefits is assumed), but will be extended in the full benefit 2 year of operation.

The three economic factors are calculated using the cost/benefit analysis,:

RT - investments of Total cost and operation in 10-year

Period or consideration,

- Communication AMI system, system included design, licenses, delivery and implementation of communication equipment, testing.

$\mathrm{R} / \mathrm{B}=\mathrm{Rt} / \mathrm{Bt}$

$R / B-$ Cost/benefit factor, Commissioning of the System,

Totalbenefitsin10yearsofoperation- $B_{t}$

$\mathrm{Bt} / \mathrm{Rt}=\mathrm{P}$

$\mathrm{G}$ are always profitable projects, with profitability in the range from 1, 2 with 5 years return of investment (compensation is not paid to customers for outages) up to

$P$ - as total benefits and costs in 10-years of operation in terms of ratio.

Cost-effectiveness of the project,

$R r=\frac{R t}{B t} *(T)$

$R r$-return investments period of time necessary for Payback period. $R t$-cost Investment,

$T$ - Period of consideration, in this case 10 years.

$$
R_{t, a}=R+\sum_{i}^{10} \frac{0.08, R i}{(1+P)_{i+1}}
$$

In every year annually recalculated benefits and costs have to be derived on the initial year using actual rate. Initial year is the system operation:

$B_{t, a}=\sum_{i}^{10} \frac{B t}{(1+P)_{i}}$

Bt, a - explains 10 years of operation Total benefits derived on the initial year.

1,7 with 3,7 years return of investment (full compensation is paid).

$B_{i}$ - benefit in the year "i"

Using 6\% actualization rate and Results of Cost/Benefit analysis are presented in Table 1 and in Fig. 3. The total cost of operation would be 137 MEur in 10 years, while the total benefit in the range from 165 MEur (compensation not paid to customers for outages) to 231 MEur (compensation fully paid to customers).

Table 1: Cost/Benefit Analysis - 10 Years of Operation Using 6\% Actualization Rate

\begin{tabular}{|l|l|l|l|l|}
\hline & $\begin{array}{l}\text { Total } \\
(\mathrm{ME})\end{array}$ & R/B & P & $\begin{array}{l}\text { R } \\
\text { (years) }\end{array}$ \\
\hline
\end{tabular}




\begin{tabular}{|l|l|l|l|l|}
\hline Investment (initial) cost & 86.40 & & & \\
\hline O\&M + depreciation costs & 50.78 & & & \\
\hline Benefit 20\% EEIA & 165.32 & 0.83 & 1.21 & 5.23 \\
\hline Benefit 21\% EEIA & 173.59 & 0.79 & 1.27 & 4.98 \\
\hline Benefit 22\% EEIA & 181.85 & 0.75 & 1.33 & 4.75 \\
\hline Benefit 23\% EEIA & 190.12 & 0.72 & 1.39 & 4.54 \\
\hline Benefit 24\% EEIA & 198.39 & 0.69 & 1.45 & 4.36 \\
\hline Benefit 25\% EEIA & 206.65 & 0.66 & 1.51 & 4.18 \\
\hline Benefit 26\% EEIA & 214.92 & 0.64 & 1.57 & 4.02 \\
\hline Benefit 27\% EEIA & 223.18 & 0.61 & 1.63 & 3.87 \\
\hline Benefit 28\% EEIA & 231.45 & 0.59 & 1.69 & 3.73 \\
\hline
\end{tabular}

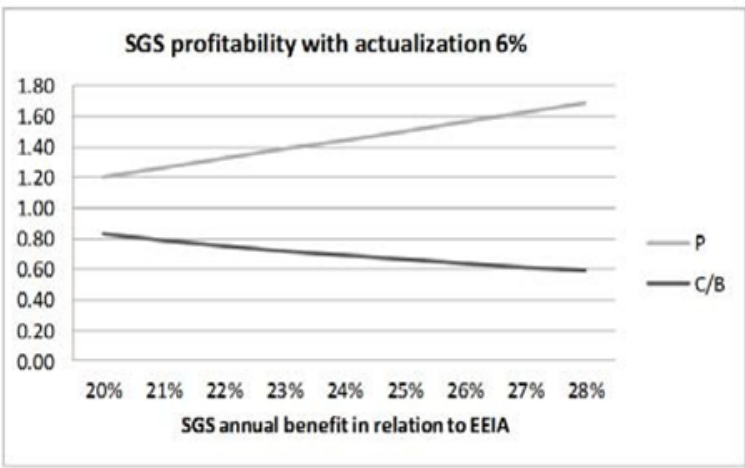

Fig. 3: Profitability of SGS with actualization

\section{Conclusion}

Safety and power quality of the supply, increasing reliability, improve power network operation provided by Smart Grid solutions. SGS Quantification of benefits is a challenge currently and comparison with related costs, also to estimate real profit investments.

Cost/benefit analysis explained According to this article, it can be concluded are Profitable investments that SGS projects. Utility is not paying any compensation Profit depends on the level of customers for outages, SGS projects will be profitable, which is unlikely, with profitability of 1,2 and reimbursement dated of 5 years, considering the life time of system operation (e.g. 10 years),. If Service is compensating benefits to customers for outages, SGS projects will be more affordable and profitable, with cost-effectiveness up to 1,7 and settlement period down to 3,7 years.

- This cost/benefit analysis which can be financially evaluated Taking into account that is considering only SGS benefits, which cannot be precisely calculated but not all potential benefits (e.g. safety on work, customer satisfaction, reducing $\mathrm{CO} 2$ pollution, etc.), should be even higher then calculated SGS profitability.

- In general, it can be assumed that SGS could be very costeffective investments, all benefits taking into account, with profitability close to 2 and return of investments in 3 years. In short, Euro double will be returned during on every capitalized the overall time of the system.

\section{References}

[1] Katic N, Strezoski V, \& Popovic D, "Commercial Benefits of DMS Software Application in Competitive Distribution", CIRED 17th Conference Barcelona, Session, 6, (2003).

[2] Katic N, Marijanovic V \& Stefani I, "Smart Grid Solutions in Distribution Networks Cost/Benefit Analysis", CICED China CIRED International Conference on Electricity Distribution, (2010).

[3] Roytelman I, Melnik V, Lee SSH \& Lugtu RL, "Multi-objective Feeder Reconfiguration by Distribution Management System", IEEE Trans. on Power System, Vol.11, No.2, (1996), pp.661 - 667.

[4] Baran ME \& Wu FF, "Network Reconfiguration in Distribution Systems for loss minimization and load balancing", IEEE Trans.
On Power Delivery, Vol.4, No.2, (1989).

[5] Giorgio DL, Paola P \& Christian N, "Minimization of Power Losses and $\mathrm{CO} 2$ emission: Accurate network data to obtain good performances of DMS systems", CIRED 20th Conference Prague, (2009).

[6] Roytelman I, Wee BK \& Lugtu RL, "Volt/Var Control for Modern Distribution Management System", IEEE Trans. on Power System, Vol.10, No.3, (1995), pp.1454-1460.

[7] Roytelman I, Wee BK, Lugtu RL, Kulas TM \& Brossart T, "Pilot Project to Estimate the Centralized Volt/Var Control Effectiveness", IEEE Trans. on Power System, Vol.13, No.3, (1998).

[8] Strezoski V, Katic N \& Janjic D, "Voltage Control Integrated in Distribution Management Systems", Electric Power Systems Research, No. 60, (2001), pp.85-97.

[9] Popovic DS, Ciric RM, "A Multi-Objective Algorithm for Distribution Networks Restoration", IEEE Trans. on Power Delivery, Vol.16, No.3, (1999), pp.1134-1141.

[10] Philipson L \& Lee Willis H, Understanding Electric Utilities and De-Regulation. Marcel Dekker Inc., (1999).

[11] Stoft S, Power System Economics, Wiley, (2002).

[12] Kirschen D \& Strbac G, Power System Economics. (John Wiley \& Sons, (2004)

[13] Katic N, Borozan V \& Halilcevic S, Power System Economics (EU project Cost Effective and Environmental Friendly Energy Systems CEFES TEMPUS Programme CD JEP-18126-2003, (2007).

[14] Romero F \& Katic N, "How to manage the impact of Distributed Generators in the Grid", AEE, Smart Grid prospects for distributors and customers, (2012).

[15] Song T, Wen ZS, Michael S, Junjie Y \& Lang T, "Online Data Integrity Attacks against Real-Time Electrical Market in Smart Grid", IEEE Transactions on Smart Grid, Vol.9, No.1, (2018), pp. $313-322$

[16] Kai M, Xuemei L, Zhixin L, Cailian C, Hao L \& Xinping G, "Cooperative Relaying Strategies for Smart Grid Communications: Bargaining Models and Solutions", IEEE Internet of Things Journal, Vol.4, No.6, (2017), pp.2315-2325. 